\title{
Enhancing synaptogenesis in diseases characterized by deficiencies in brain synapses
}

\section{Richard J. Wurtman*}

Department of Brain and Cognitive Sciences, Massachusetts Institute of Technology, Cambridge, MA, USA *Correspondence: dick@mit.edu

The loss of hippocampal and cortical synapses, resulting from impaired synaptogenesis, accelerated synaptic degeneration, or both, is one of the earliest neuropathologic findings in Alzheimer's Disease and is the finding that best correlates with cognitive symptoms (DeKosky and Scheff, 1990; Terry et al., 1991; Selkoe, 2002). A similar decrease in brain synapses is an early finding in an animal model of $\mathrm{AD}$ which overproduces A-beta peptides (Jacobsen et al., 2006), and aggregates of such peptides, applied locally to the brain, can also damage synapses, distort neurites, and decrease the numbers of the dendritic spines which are essential precursors for glutamatergic synapses (Jacobsen et al., 2006; Spires-Jones et al., 2007; Knobloch and Mansuy, 2008). These observations have supported the widely-held view that a treatment that would block the synthesis of A-beta or remove it from the circulation, might - by depleting its levels in brain - slow the loss of synapses in $\mathrm{AD}$ and thereby sustain cognitive functions in patients. A generation of creative and diligent researchers has provided us with abundant information about A-beta's synthesis, fates, and toxic effects, and this information has been used to generate rationally-designed drug candidates for treating the disease. However to date none of these candidates - even ones shown to reduce brain levels of A-beta oligomers and senile plaques - has been successful in sustaining cognition.

In the future perhaps another drug candidate might succeed both in reducing brain levels of A-beta peptides and ameliorating the dementia of Alzheimer's Disease; mankind appears united in the hope that this will be the case. However in the interim might there be additional therapeutic strategies which we can pursue in parallel which, if successful, might provide patients with more benefit than they presently obtain from the acetylcholinesterase inhibitors or glutamate antagonist now in use?
One such strategy might entail finding a treatment that, by accelerating synaptogenesis, would diminish the net loss of hippocampal and cortical synapses caused by AD. There are a number of loci at which such a treatment might work: For example, it might amplify the flux of free calcium into stimulated dendrites, or activate receptors that control key steps in forming dendritic spines, or increase the synthesis of pre- or post-synaptic proteins, or generate more synaptic membrane, the main constituent of synapses. One such treatment, described below, has been proposed based on studies in experimental animals, and is currently being tested in patients. Its intent is to promote synaptogenesis by administering phosphatide precursors which, in test animals, increase the production of synaptic membrane and dendritic spines (Wurtman et al., 2006; Sakamoto et al., 2007). The three precursors required to form the phosphatides - uridine; an omega-3 fatty acid such as docosahexaenoic acid (DHA); and choline - all readily cross the blood-brain barrier (Wurtman et al., 2009).

Synaptic membrane is composed principally of phospholipids - particularly the phosphatides phosphatidylcholine (PC), phosphatidylethanolamine (PE), phosphatidylserine (PS), and phosphatidylinositol (PI) - as well as characteristic pre-and post-synaptic proteins. Formation of the phosphatides from their three circulating precursors is mediated by enzymes that exhibit relatively low affinities for these substrates, and thus are unsaturated at the precursor concentrations normally present in the blood and brain. The circulating choline is obtained from various foods and is also synthesized in and secreted from the liver (Wurtman, 2009; Wurtman et al., 2009); the uridine, also produced in and released from the liver, is present in many foods in the form of RNA, however there is no satisfactory evidence that uridine in dietary RNA (unlike that present as uridine monophosphate [UMP] in mothers' milk and infant formulas) actually enters the circulation; the omega- 3 fatty acids, as essential nutrients, must be largely or entirely obtained from the diet (Cansev and Wurtman, 2007). Because the enzymes that initiate the conversion of these compounds to $\mathrm{PC}$ are unsaturated, the administration of choline increases the synthesis and brain levels of its phosphorylated product phosphocholine; that of uridine increases UTP and CTP; and that of DHA increases the proportion of diacylglycerol (DAG) that contains this omega-3 fatty acid.

The phosphocholine and CTP formed when animals receive uridine plus choline then combine to form CDP-choline, which in turn combines with DHA-containing DAG to form PC. Treatment of rats or gerbils with supplemental choline, UMP, and an omega-3 fatty acid for several weeks is associated with substantial increases in levels of PC per brain or per brain cell, as well as roughly-proportionate increases in the other phosphatides (Wurtman et al., 2006); moreover the effects of giving all three precursors tend to be greater than the sum of the effects of giving each separately. Animals so treated also exhibit significant improvements in memory functions, as assessed using the Morris water maze and T- or Y-mazes (Holguin et al., 2008a,b).

Administration of the three phosphatide precursors also increases brain levels of pre- and post-synaptic proteins (such as synapsin, synaptophysin, PSD-95, and mGluR) (Wurtman et al., 2006; Cansev and Wurtman, 2007) as well as the numbers of dendritic spines (Sakamoto et al., 2007). These effects are due in part to an additional effect of the pyrimidine uridine (Pooler et al., 2005): Besides serving, indirectly, as a CTP precursor in cytidine-dependent phosphatide synthesis, uridine and its phosphorylated products (e.g., UTP) are also agonists for $\mathrm{P} 2 \mathrm{Y}$ receptors that affect neuronal protein synthesis (Pooler et al., 2005). (These receptors, parenthetically, are deficient in parietal cortex of patients 
with AD [Lai et al., 2008]). DHA alone can also stimulate neurite outgrowth (Darios and Davletov, 2006) and dendritic spine formation (Sakamoto et al., 2007), possibly by activating other receptors.

Existing technologies have not allowed the direct measurement of hippocampal synapse formation in animals receiving the three phosphatide precursors. However the consensus among synaptologists seems to be that an increase in dendritic spines as produced by the precursors virtually always leads to an increase in synapses: It has been estimated that $90 \%$ or more of the spines become synapses (c.f. Alvarez and Sabatini, 2007; Arellano et al., 2007; Toni et al., 2007).

In an initial clinical trial, 110 patients with very mild or mild $\mathrm{AD}$ received the precursors for 6 weeks while an equal number served as controls; those in the treated group exhibited a statistically-significant improvement in memory compared with control subjects (Scheltens et al., 2010). It remains to be determined whether this improvement was, in fact, associated with an increase in the numbers of cortical and hippocampal synapses. Three additional largescale trials are underway; these also include measurements of biomarkers for $\mathrm{AD}$ and for assessing synaptic density. If indeed the improvement in memory is confirmed in future studies it may be possible to amplify this response by using novel, more potent P2Y receptor agonists, perhaps given along with the phosphatide precursors to enhance production of synaptic membrane.

\section{REFERENCES}

Alvarez, V.A., and Sabatini, B. L. (2007). Anatomical and physiological plasticity of dendritic spines. Annu. Rev. Neurosci. 30, 79-97.
Arellano, J. I., Espinosa, A., Fairen, A., Yuste, R., and DeFelipe, J. (2007). Non-synaptic dendritic spines in neocortex. Neuroscience 145, 464-469.

Cansev, M., and Wurtman, R. J. (2007). Chronic administration of docosahexaenoic acid or eicosapentaenoic acid, but not arachidonic acid, alone or in combination with uridine increases brain phosphatide and synaptic proteins levels in gerbils. Neuroscience 148, 421-431.

Darios, F., and Davletov, B. (2006). Omega-3 and Omega-6 fatty acids stimulate cell membrane expansion by acting on syntaxin 3. Nature 440, 813-817.

DeKosky, S. T., and Scheff, S. W. (1990). Synapse loss in frontal cortex biopsies in Alzheimer's disease: correlation with cognitive severity. Ann. Neurol. 27, 457-464.

Holguin, S., Martinez, J., Chow, D., and Wurtman, R. (2008a). Dietary uridine enhances the improvement in learning and memory produced by administering DHA plus choline to gerbils. FASEB J. 22, 3938-3946.

Holguin, S., Huang, Y, Liu, J., and Wurtman, R. (2008b). Chronic administration of DHA and UMP improves the impaired memory of environmentally impoverished rats. Behav. Brain Res. 191, 11-16.

Jacobsen, J. S., Wu, C-C., Redwine, J. M., Comery, T. A., Arias, R., Bowlby, M., Martone, R., Morrison, J. H., Pangalos, M. N., Reinhart, P. H., and Bloom, F. E. (2006). Early-onset behavioral and synaptic deficits in a mouse model of Alzheimer's disease. Proc. Natl. Acad. Sci. U.S.A. 103, 5161-5166.

Knobloch, M., and Mansuy, I. M. (2008). Dendritic spine loss and synaptic alterations in Alzheimer's disease. Mol. Neurobiol. 37, 73-82.

Lai, M. K. P., Tan, M. G. K., Kirvell, S., JHobbs, C., Lee, J., Esiri, M. M., Chen, C. P., and Francis, P. T. (2008). Selective loss of P2Y2 nucleotide receptor immunoreactivity is associated with Alzheimer's disease neuropathology. J. Neural Transm. 115, 1165-1172.

Pooler, A. M., Guez, D. H., Benedictus, R., and Wurtman, R. J. (2005). Uridine enhances neurite outgrowth in NGF-differentiated PC12 cells. Neuroscience 134 207-214.

Sakamoto, T., Cansev, M., and Wurtman, R. J. (2007). Oral supplementation with docosahexaenoic acid uridine 5'-monophosphate increases dendritic spine density in adult gerbil hippocampus. Brain Res. 1182, 50-59.
Scheltens, P., Kamphuis, P. J. G. H., Verhey, F. R. J., Olde Rikkert, M., Wurtman, R. J., Wilkinson, D., Twisk, J.W. A., and Kurz,A. (2010). The efficacy of a medical food in early Alzheimer's disease: a randomized controlled trial. Alzheimers Dement. 6, 1-10.

Selkoe, D. J. (2002). Alzheimer's disease in a synaptic failure. Science 298, 789-791.

Spires-Jones, T. L., Meyer-Luehmann, M., Osetek, J. D., Jones, P. B., and Stern, E. A. (2007). Impaired spine stability underlies plaque-related spine loss in an Alzheimer's disease mouse model. Am. J. Pathol. 171, 1304-1311.

Terry, R. D., Masliah, E., Salmon, D. P., Butters, N., DeTeresa, R., Hill, R., Hansen, L. A., and Katzman, R. (1991). Physical basis of cognitive alterations in Alzheimer's disease: synapse loss is the major correlate of cognitive impairment. Ann. Neurol. 30, 572-580.

Toni, N., Teng, E. M., and Bushong, E. A. (2007). Synapse formation on neurons born in the adult hippocampus. Nat. Neurosci. 10, 727-734.

Wurtman, R., Cansev, M., and Ulus, I. (2009). "Choline and its products acetylcholine and phosphatidylcholine," in Neural Lipids, Handbook of Neurochemistry and Molecular Neurobiology, Vol. 8, Part: 3, Chapter: 18. ed.A. Lajtha (Berlin, Heidelberg: Springer-Verlag), 445-501.

Wurtman, R. J. (2009). Use of phosphatide precursors to promote synaptogenesis. Annu. Rev. Nutr. 29 , 59-87.

Wurtman, R. J., Ulus, I. H., Cansev, M., Watkins, D. J., Wei, L., and Marzloff, G. (2006). Synaptic proteins and phospholipids are increased in gerbil brain by administering uridine plus docosahexaenoic acid orally. Brain Res. 1088, 83-92.

Received: 20 October 2010; accepted: 29 October 2010; published online: 18 November 2010.

Citation: Wurtman RJ (2010) Enhancing synaptogenesis in diseases characterized by deficiencies in brain synapses. Front. Psychiatry 1:147. doi: 10.3389/fpsyt.2010.00147 Thisarticle was submitted to Frontiers in Neurodegeneration, a specialty of Frontiers in Psychiatry.

Copyright $\odot 2010$ Wurtman. This is an open-access article subject to an exclusive license agreement between the authors and the Frontiers Research Foundation, which permits unrestricted use, distribution, and reproduction in any medium, provided the original authors and source are credited. 